
\title{
$\angle$ Research Suare \\ Early Complications of Anterior Cervical Fusion Using Zero-profile Implants: Analysis of 193 Consecutive Cases
}

Fernando Luiz Rolemberg Dantas ( $\nabla$ dantasfernando2@gmail.com )

Biocor Instituto

Bruno Lacerda Sandes

Biocor Instituto

François Dantas

Biocor Instituto

Antônio Carlos Vieira Caires

Biocor Instituto

Gustavo Agra Cariri

Biocor Instituto

Gilberto de Almeida Fonseca Filho

Biocor Instituto

Ricardo Vieira Botelho

lamspe

Research article

Keywords: Anterior cervical fusion, complications, dysphagia, Zero-profile implant

Posted Date: January 23rd, 2020

DOl: https://doi.org/10.21203/rs.2.21693/v1

License: (1) This work is licensed under a Creative Commons Attribution 4.0 International License. Read Full License 


\section{Abstract}

Background: Anterior access to the cervical spine is considered safe, with the most common complication being dysphagia. The objective of this study is to describe early complications of anterior cervical fusion using Zero-profile implants in a neurosurgery department and compare these with the literature. Methods: In a retrospective study, we analyzed data of patients diagnosed with cervical spondylodiscoarthrosis at a single center between January 2011 and January 2017 who underwent anterior cervical fusion using Zero-profile implants. The analyzed demographic data included age, sex, symptoms, number of operated levels, time of preoperative symptoms, type of symptom and length of hospital stay. Immediate postoperative complications were noted. Results: A total of 193 consecutively operated patients were included. Of the total, 106 patients were female (54.9\%). The average age of the patients was 52.7 years. Average hospitalization was 3.20 days and the average number of levels was 1.68. Complications were noted in 57 patients (29.5\%). Older patients had more complications (mean 55.5 years versus 51.5 ). The average length of stay was longer for patients with complications. The average number of operated levels was 1.84 in patients with complications and 1.61 in those who did not complicate. The most common complications were dysphagia (9.32\%) and dysphonia (5.69\%). We had 1 case of C5 monoparesis and 1 case of epidural hematoma, considered serious complications. Conclusions: Postoperative dysphagia and dysphonia were the most common complications in our series. Risk factors for complications were advanced age and number of operated levels.

\section{Introduction}

Anterior cervical discectomy and fusion were first described by Smith and Robinson in 1958 for treating radiculopathy and cervical spondylotic myelopathy. ${ }^{1}$ Anterior access to the cervical spine is considered safe, despite the risk of life-threatening complications such as compressive cervical hematoma. The most commonly described complication in the literature is dysphagia, ${ }^{2}$ and it is believed that the prevalence of complications is underestimated.

Zero-profile spinal fusion implants have been developed to reduce the rate of complications associated with the placement of anterior cervical plates. These cages can be fixed directly to the endplates of the vertebral bodies, without the need for titanium anterior plating, causing less friction with the esophagus. The stability and effectiveness of Zero-profile implants are comparable to those of the classical technique using plates and screws. ${ }^{3}$ In this study, we described early complications of anterior cervical fusion using Zero-profile implants in a neurosurgery department and compared these with the complications reported in literature.

\section{Material And Methods}

In this retrospective study, we analyzed data of patients diagnosed with cervical spondylodiscoarthrosis at the Biocor Instituto between January 2011 and January 2017 who underwent anterior cervical fusion using a Zeroprofile implant. The surgeries were performed by 4 neurosurgeons, and all patients wore a cervical collar following surgery for at least 4 weeks.

The inclusion criteria were patients with signs and symptoms of cervical radiculopathy or cervical spondylotic myelopathy who were non-responsive to clinical treatment. The exclusion criteria were the presence of tumors, 
trauma, or infections and the need for simultaneous anterior and posterior surgeries.

The analyzed demographic data included age, sex, symptoms, number of operated levels, time of preoperative symptoms, type of symptom (myelopathic or radicular), length of hospital stay, and types of complications.

Data related to age, length of hospital stay and number of operated levels were tested for normality using the Kolmogorov-Smirnov test ${ }^{4,5}$ and it was concluded that they did not fit a normal distribution ( $p$-value $\left.<0.05\right)$. Therefore, the non-parametric Mann-Whitney $U$ test $(a=5 \%)$, comparing two independent groups, ${ }^{6,7}$ was conducted on samples with and without complications for each of the three variables.

Surgery was performed under general anesthesia with the patient in the horizontal dorsal decubitus potation, with slight cervical hyperextension, and cushions placed under the interscapular region. Right anterior cervicotomy was performed with the dissection of pharyngeal and esophageal structures medially and neurovascular structures laterally. The levels to be operated were identified via fluoroscopy. Microsurgical discectomy was performed, and the spinal fusion cage was placed between the vertebral bodies after spinal cord decompression. An inorganic graft derived from small bone fragments removed during the surgery was used. Adequate positioning of the spacer was confirmed via fluoroscopy. All patients received antibiotics $1 \mathrm{~h}$ before and $24 \mathrm{~h}$ after the surgery.

Postoperative control radiographs were obtained from all patients before hospital discharge, and the number and type of complications in the immediate postoperative period before discharge were analyzed. The assessed complications included dysphagia, dysphonia, odynophagia, motor deficit, dysesthesia, sphincter alterations, surgical-site hematoma, and need for reoperation. The patients were evaluated during hospitalization within the immediate postoperative period.

This study was approved by the Research Ethics Committee of Biocor Instituto.

\section{Results}

A total of 193 consecutive patients who underwent surgery for anterior cervical fusion using Zero-profile implants were included in the study. Of the total, 106 (54.9\%) were females and 87 (45.1\%) were males. Mean patient age was $52.7 \pm 1.9$ years, and median (range) age was $51(23-88)$ years.

The most common symptom in the preoperative period was radiculopathy $(n=147,76.2 \%)$, followed by myelopathy $(n=31,16.1 \%)$ and combined symptoms (radiculopathy and myelopathy, $n=15,7.8 \%)$. Mean duration of symptoms was $11.8 \pm 2.4$ months.

Mean (range) hospitalization duration was $3.20 \pm 0.44$ (1-30) days, and mean (range) number of operated levels was $1.68 \pm 0.09(1-4)$ (Fig. 1).

Immediate postoperative complications (both mild and severe) were observed in 57 (29.5\%) patients. The most common complications were dysphagia $(n=18,9.32 \%)$ and dysphonia $(n=11,5.69 \%)$. Combined symptoms of mild dysphagia and dysphonia occurred in $9(4.66 \%)$ patients. There were no cases of permanent dysphagia or dysphonia. Monoparesis of C5 occurred in $1(0.51 \%)$ patient, and paraparesis secondary to epidural hematoma occurred in $1(0.51 \%)$ patient; both these can be considered severe complications. Reoperation was required in 
2 patients: epidural hematoma associated with paraparesis in 1 (Fig. 2) and displacement of the cage in 1. There were no cases of perioperative or immediate postoperative death or surgical-site hematoma, which are commonly reported in the literature. The complications in this case series are summarized in Table 1.

Table 1

Complications in the study population

\begin{tabular}{|lll|}
\hline Type $(\mathbf{N}=193)$ & N & $\%$ \\
\hline Dysphagia & 18 & 9.3 \\
\hline Dysphonia & 11 & 5.7 \\
\hline Mild dysphonia/dysphagia & 9 & 4.7 \\
\hline Odynophagia & 7 & 3.6 \\
\hline Arm paresthesia & 2 & 1.0 \\
\hline Urinary retention & 2 & 1.0 \\
\hline Cervicalgia/displacement of the fixation system & 1 & 0.5 \\
\hline Dysphonia/left arm paresthesia & 1 & 0.5 \\
\hline Left brachial monoparesis at C5 & 1 & 0.5 \\
\hline Epidural hematoma associated with paraparesis at C6-T8 & 1 & 0.5 \\
\hline Worsening of bilateral brachial paresis & 1 & 0.5 \\
\hline Right facial paresis & 1 & 0.5 \\
\hline Left arm paresis/right arm hypoesthesia & 1 & 0.5 \\
\hline Reoperation because of a displaced cage & 1 & 0.5 \\
\hline Total & 57 & $29.5 \%$ \\
\hline
\end{tabular}

The rate of complications was non-significantly higher in females (54.9\%) and significantly higher in older patients (mean age, 55.5 years for patients with complications and 51.5 years for those without complications; $p=0.031$ ). Mean length of hospital stay was 3.88 days for patients with complications and 2.91 days for those without complications $(p<0.001)$. The average number of operated levels was 1.84 in patients with complications and 1.61 in those without complications $(p=0.021)$. The types of complications according to age, length of hospital stay, and number of operated levels are shown in Table 2. 
Table 2

Complications according to age, length of hospital stay, and the number of operated levels

\begin{tabular}{|c|c|c|c|c|c|c|c|c|c|c|}
\hline \multicolumn{2}{|c|}{ Complications } & \multirow{2}{*}{$\begin{array}{l}\text { Mean } \\
51.5\end{array}$} & \multirow{2}{*}{$\begin{array}{l}\text { Median } \\
50\end{array}$} & \multirow{2}{*}{$\begin{array}{l}\text { Standard } \\
\text { deviation } \\
13.4\end{array}$} & \multirow{2}{*}{$\begin{array}{l}\text { CV } \\
26 \%\end{array}$} & \multirow{2}{*}{$\begin{array}{l}\text { Min } \\
23\end{array}$} & \multirow{2}{*}{$\begin{array}{l}\text { Max } \\
88\end{array}$} & \multirow{2}{*}{$\begin{array}{l}\mathbf{N} \\
136\end{array}$} & \multirow{2}{*}{$\begin{array}{l}95 \% \\
\mathrm{Cl} \\
2.3\end{array}$} & \multirow{2}{*}{$\begin{array}{l}\begin{array}{l}\mathrm{p}- \\
\text { value }\end{array} \\
0.031\end{array}$} \\
\hline Age & $\begin{array}{l}\text { No } \\
\text { complications }\end{array}$ & & & & & & & & & \\
\hline & $\begin{array}{l}\text { Complications } \\
\text { present }\end{array}$ & 55.5 & 55 & 13.0 & $23 \%$ & 28 & 81 & 57 & 3.4 & \\
\hline \multirow{2}{*}{$\begin{array}{l}\text { Length } \\
\text { of } \\
\text { hospital } \\
\text { stay }\end{array}$} & $\begin{array}{l}\text { No } \\
\text { complications }\end{array}$ & 2.91 & 2 & 2.70 & $93 \%$ & 1 & 20 & 136 & 0.45 & \multirow[t]{2}{*}{$\begin{array}{l}< \\
0.001\end{array}$} \\
\hline & $\begin{array}{l}\text { Complications } \\
\text { present }\end{array}$ & 3.88 & 3 & 3.94 & $102 \%$ & 1 & 30 & 57 & 1.02 & \\
\hline \multirow{2}{*}{$\begin{array}{l}\text { Number } \\
\text { of } \\
\text { operated } \\
\text { levels }\end{array}$} & $\begin{array}{l}\text { No } \\
\text { complications }\end{array}$ & 1.61 & 2 & 0.63 & $39 \%$ & 1 & 3 & 136 & 0.11 & \multirow[t]{2}{*}{0.021} \\
\hline & $\begin{array}{l}\text { Complications } \\
\text { present }\end{array}$ & 1.84 & 2 & 0.65 & $35 \%$ & 1 & 4 & 57 & 0.17 & \\
\hline
\end{tabular}

\section{Discussion}

Anterior cervical fusion was first described by Smith and Robinson in 1958 for treating cervical spondylodiscoarthrosis. ${ }^{1}$ The anterior approach allows treating several conditions, particularly those related to spondylodiscoarthrosis. ${ }^{8}$ Classically, this approach has been performed with plates and screws, and Zeroprofile implants are a relatively recent surgical option with lower complication rates. 3,9

A plethora of complications of anterior cervical fusion with varying prevalence rates have been reported in the literature, including dysphagia, recurrent laryngeal nerve palsy, esophageal or laryngeal laceration, Horner syndrome, thoracic duct injury, pneumothorax, vessel injuries (vertebral artery, carotid artery, or jugular vein), epidural hematoma, epidural abscess, surgical-site hematoma, spondylodiscitis, seroma, dural fistula, meningitis, spinal cord contusion, nerve root injury, worsening of radicular or myelopathic symptoms, displacement of surgical materials, and postoperative mechanical instability of the cervical spine. ${ }^{10-30}$

In a retrospective study, Fountas et al. ${ }^{31}$ evaluated complications in 1,015 consecutive patients who underwent anterior cervical fusion; the most common complications included isolated dysphagia (9.5\%) and surgical-site hematoma (5.6\%). Dysphagia improved completely within 7 days in most patients. The number of operated levels was considered a risk factor for dysphagia, and the rate of complications was higher in surgeries involving 3 or more levels. In addition, there was accidental esophageal perforation in $0.3 \%$ cases and worsening of pre-existing myelopathic symptoms in $0.2 \%$ cases.

Starmer et al. $^{2}$ performed a comprehensive review, the largest in the literature, involving $1,649,871$ patients who underwent anterior cervical fusion and found that postoperative dysphagia occurred in $2 \%$ cases. Dysphagia was more common in patients $>65$ years of age and was associated with dysphonia, unilateral vocal cord paralysis, and aspiration pneumonia. 
Overley et al. ${ }^{32}$ performed a retrospective cohort study including 80 patients who underwent anterior cervical fusion and compared the use of stand-alone cages $(n=40)$ and cervical plates $(n=40)$. Patients who received cages developed no complications (0/40), whereas 10\% (4/40) patients who received plates developed complications. There were 3 cases of dysphagia. Myelopathic symptoms occurred predominantly compared with radicular symptoms in both groups, which contradicts the findings in our case series.

The classical risk factors for dysphagia following anterior cervical fusion include older age, increased peroperative time, multiple operated levels, and reoperations. ${ }^{33-38}$

Liu et al. ${ }^{39}$ performed a systematic review of 59 studies and proposed identifying risk factors for immediate postoperative dysphagia following anterior cervical fusion. The modifiable risk factors for dysphagia were: prolonged peroperative time, use of orotracheal tube pilot balloon filled with a pressure $>20 \mathrm{mmHg}$, use of plates and screws, smoking, history of psychiatric disorders, angle at C2-C7, prevertebral tissue edema, and recurrent laryngeal nerve palsy. Non-modifiable risk factors for dysphagia were: older age, female sex, higher number of operated levels, reoperations, prolonged duration of preoperative pain, and arthrodesis at higher levels. The study concluded that Zero-profile implants reduce the prevalence of dysphagia compared with plates and screws.

Recently, Yang et al. ${ }^{40}$ performed a meta-analysis of 30 studies on arthrodesis using Zero-profile implants and showed that the prevalence of postoperative dysphagia ranged from $0-76 \%$ and the rate of persistent dysphagia ranged from $0-7 \%$. Furthermore, the prevalence of this complication increased with the number of operated levels.

Yin et al. ${ }^{3}$ performed another meta-analysis and literature review and confirmed that the prevalence of dysphagia decreased using Zero-profile implants compared with that using plates and screws, particularly in the first 3 months following surgery.

In our series of 193 patients consecutively treated with Zero-profile implants at a single center, the rate of dysphagia was $9.3 \%$ in the immediate postoperative period. The risk factors for this complication were advanced age and increased number of operated levels.

The present study has some limitations. First, the study was retrospective through the analysis of medical records. Second, the study was conducted at a single center and surgeries were performed by 4 distinct surgeons, although the surgical technique was similar. Finally, complications were assessed only during the hospitalization period and subsequent follow-up of the patients was not included in this study.

\section{Conclusions}

The most common postoperative complications in our series were dysphagia and dysphonia, which were transient in all cases. The length of hospital stay was longer in patients with complications, and the rate of complications increased with age and number of operated levels.

\section{Declarations}




\section{Ethics approval and consent to participate}

This study was performed in accordance with the Declaration of Helsinki, and it was approved by the Research Ethics Committee of Biocor Instituto.

\section{Consent for publication}

Written informed consent was obtained from the patients related to the images of the article, even though images are entirely unidentifiable.

\section{Availability of data and materials}

The datasets used and/or analysed during the current study are available from the corresponding author on reasonable request.

\section{Competing interests}

The authors declare that they have no known competing financial interests or personal relationships that could have appeared to influence the work reported in this paper.

\section{Funding}

This research did not receive any specific grant from funding agencies in the public, commercial, or not-forprofit sectors.

\section{Author's contributions}

1- FLRD

Conceptualization, data curation, formal analysis, supervision, project administration

2- BLS

Conceptualization, data curation, formal analysis, methodology, project administration

3- FD

Data curation, formal analysis, methodology, supervision, statistics

4- ACVC

Data curation, investigation

5- GAC

Data curation, investigation

6- GAFF 
Formal analysis

7- RVB

Supervision, methodolgy

\section{Acknowledgements}

The authors thank Marina Salim Dantas for her assistance, especially with the statistical analysis.

\section{References}

1. Smith GW, Robinson RA. The treatment of certain cervical-spine disorders by anterior removal of the intervertebral disc and interbody fusion. J Bone Joint Surg Am. 1958;40:607-624.

2. Starmer HM, Riley LH, Hillel AT, Lee M, Best SR, Gourin CG. Dysphagia, short-term outcomes, and cost of care after anterior cervical disc surgery. Dysphagia. 2014;29:68-77. https://doi.org/10.1007/s00455-0139482-9.

3. Yin M, Ma J, Huang Q, Xia Y, Shen Q, Zhao C, Tao J, Chen N, Yu Z, Ye J, Mo W, Jiao J. The new Zero-P implant can effectively reduce the risk of postoperative dysphagia and complications compared with the traditional anterior cage and plate: a systematic review and meta-analysis. BMC Musculoskelet Disord. 2016;17:430. https://doi.org/10.1186/s12891-016-1274-6.

4. Kolmogorov AN. Sulla determinazione empirica di una legge di distribuzione. Giornale dell'Istituto Italiano degli Attuari. 1933;4:83-91.

5. Smirnov NV. On the Estimation of the Discrepancy Between Empirical Curves of Distribution for Two Independent Samples. Bul Math de I'Univ de Moscou. 1939;2: 3-14.

6. Mann HB, Whitney DR. On a Test of Whether One of Two Random Variables is Stochastically Larger Than the Other. The Annals of Mathematical Statistics. 1947;18(1):50-60. https://doi.org/10.1214/aoms/1177730491.

7. Wilcoxon F. Individual comparisons by ranking methods. Biometrics Bulletin. 1945;1:80-83.

8. Matz PG, Holly LT, Groff MW, Vresilovic EJ, Anderson PA, Heary RF, Kaiser MG, Mummaneni PV, Ryken TC, Choudhri TF, Resnick DK. Indications for anterior cervical decompression for the treatment of cervical degenerative radiculopathy. J Neurosurg Spine. 2009;11:174-182. https://doi.org/10.3171/2009.3.SPINE08720.

9. Lee MJ, Bazaz R, Furey CG, Yoo J. Influence of anterior cervical plate design on dysphagia: a 2-year prospective longitudinal follow-up study. J Spinal Disord Tech. 2005;18:406-409. https://doi.org/10.1097/01.bsd.0000177211.44960.71.

10. Fielding JW. Complications of anterior cervical disk removal and fusion. Clin Orthop. 1992;284:10-13.

11. Flynn TB. Neurologic complications of anterior cervical interbody fusion. Spine. 1982;7:536-539.

12. Taylor BA, Vaccaro AR, Albert TJ. Complications of anterior and posterior surgical approaches in the treatment of cervical degenerative disc disease. Semin Spine Surg. 1999;11:337-346.

13. Tew JM, Mayfield FH. Complications of surgery of the anterior cervical spine. Clin Neurosurg. 1976;23:424-434. 
14. Robinson RA, Walker E, Ferlic DC, Wiecking DK. The results of anterior interbody fusion of the cervical spine. J Bone Joint Surg Am. 1962;44:1569-1586.

15. Graham JJ. Complications of cervical spine surgery: a five year report on a survey of the membership of the cervical spine research society by the morbidity and mortality committee. Spine. 1989;14:1046-1050.

16. Hart AKE, Greinwald JH, Shaffrey Cl, Postma GN. Thoracic duct injury during anterior cervical discectomy: a rare complication. J Neurosurg. 1998;88:151-154.

17. Jung A, Schramm J, Lahnerdt K, Herberhold C. Recurrent laryngeal nerve palsy during anterior cervical spine surgery: a prospective study. J Neurosurg Spine. 2005;2:123-127.

https://doi.org/10.3171/spi.2005.2.2.0123.

18. Karim A, Knapp J, Nanda A. Internal jugular venous thrombosis as a com- plication after an elective anterior cervical discectomy: case report. Neurosurgery. 2006;59:E705. https://doi.org/10.1227/01.NEU.0000229056.02698.6E.

19. Jenis LG, Leclair WJ. Late vascular complication with anterior cervical discectomy and fusion. Spine. 1994;19:1291-1293. https://doi.org/10.1097/00007632-199405310-00019.

20. Fountas KN, Kapsalaki EZ, Johnston KW. Cerebrospinal fluid fistula secondary to dural tear in anterior cervical discectomy and fusion. Spine. 2005;30:E227-E280.

https://doi.org/10.1227/01.NEU.0000229056.02698.6E.

21. Violon P, Patay Z, Braeckeveldt J, Pirotte B, Kentos A, Brotchi J, Balériaux D. An atypical infectious complication of an anterior cervical surgery. Neuroradiology. 1997;39:278-281. https://doi.org/10.1007/s002340050409.

22. Kulkarni AG, Hee HT. Adjacent level discitis after anterior cervical discectomy and fusion (ACDF): a case report. Eur Spine J. 2006;15:559-563. https://doi.org/10.1007/s00586-005-0003-x.

23. Kraus DR, Stauffer ES. Spinal cord injury as a complication of elective anterior cervical fusion. Clin Orthop. 1975;112:130-141.

24. Cavanagh SP, Tyagi A, Marks P. Extrusion of BOP-B graft orally following anterior cervical discectomy and fusion. Br J Neurosurg. 1996;10:417-418. https://doi.org/10.1080/02688699647393.

25. Stieber JR, Brown K, Donald DG, Cohen JD. Anterior cervical decompression and fusion with plate fixation as an outpatient procedure. Spine J. 2005;5:503-507. https://doi.org/10.1016/j.spinee.2005.01.011.

26. Fountas KN, Kapsalaki EZ, Machinis T, Robinson JS. Extrusion of a screw into the gastrointestinal tract after anterior cervical spine plating. J Spinal Disord Tech. 2006;19:199-203. https://doi.org/10.1097/01.bsd.0000164164.11277.49.

27. Daentzer D, Deinsberg W, Boker DK. Vertebral artery complications in anterior approaches to the cervical spine: report of two cases and review of literature. Surg Neurol. 2003;59:300-309. https://doi.org/10.1016/s0090-3019(03)00113-7.

28. Garcia Alzamora M, Rosahl SK, Lehmberg J, Klisch J. Life-threatening bleeding from a vertebral artery pseudoaneurysm after anterior cervical spine approach. Endovascular repair by a triple-stent-in-stent method: case report. Neuroradiology. 2005;47:282-286. https://doi.org/10.1007/s00234-005-1343-2.

29. Burke JP, Gerszten PC, Welch WC. latrogenic vertebral artery injury during anterior cervical spine surgery. Spine J. 2005;5:508-514. https://doi.org/10.1016/j.spinee.2004.11.015. 
30. Zeidman SM, Ducker TB, Raycroft J. Trends and complications in cervical spine surgery:1989 -1993. J Spinal Disord Tech. 1997;10:523-526.

31. Fountas KN, Kapsalaki EZ, Nikolakakos LG, Smisson HF, Johnston KW, Grigorian AA, Lee GP, Robinson Jr JS. Anterior cervical discectomy and fusion associated complications. Spine. 2007;32:2310-2317. https://doi.org/10.1097/BRS.0b013e318154c57e.

32. Overley SC, Merrill RK, Leven DM, Meaike JJ, Kumar A, Qureshi SA. A matched cohort analysis comparing stand-alone cages and anterior cervical plates used for anterior cervical discectomy and fusion. Global Spine J. 2017;7:394-399. https://doi.org/10.1177/2192568217699211.

33. Anderson KK, Arnold PM. Oropharyngeal dysphagia after anterior cervical spine surgery: a review. Global Spine J. 2013;3:273-286. https://doi.org/10.1055/s-0033-1354253.

34. Hayashi T, Fujiwara Y, Sakai H, Maeda T, Ueta T, Shiba K. Risk factors for severe dysphagia in acute cervical spinal cord injury. Spinal Cord. 2017;55:940-943. https://doi.org/10.1038/sc.2017.63.

35. Shin JC, Yoo JH, Lee YS, Goo HR, Kim DH. Dysphagia in cervical spinal cord injury. Spinal Cord. 2011;49:1008-1013.

36. Kalb S, Reis MT, Cowperthwaite MC, Fox DJ, Lefevre R, Theodore N, Sonntag VK. Dysphagia after anterior cervical spine surgery: incidence and risk factors. World Neurosurg. 2012;77:183-187. https://doi.org/10.1016/j.wneu.2011.07.004.

37. Kirshblum S, Johnston MV, Brown J, O'Connor KC, Jarosz P. Predictors of dysphagia after spinal cord injury. Arch Phys Med Rehab. 1999;80:1101-1105. https://doi.org/10.1016/s0003-9993(99)90068-0.

38. Joaquim AF, Murar J, Savage JW, Patal AA. Dysphagia after anterior cervical spine surgery: a systematic review of potential preventative measures. Spinal J. 2014;4:2246-2260.

https://doi.org/10.1016/j.spinee.2014.03.030.

39. Liu J, Hai Y, Kang N, Chen X, Zhang Y. Risk factors and preventative measures of early and persistent dysphagia after anterior cervical spine surgery: a systematic review. Eur Spine J. 2018;27:1209-1218. https://doi.org/10.1007/s00586-017-5311-4.

40. Yang Y, Ma L, Liu H, Xu M. A meta-analysis of the incidence of patient-reported dysphagia after anterior cervical decompression and fusion with the zero-profile implant system. Dysphagia. 2016;31:134-145. https://doi.org/10.1007/s00455-015-9681-7.

\section{Figures}




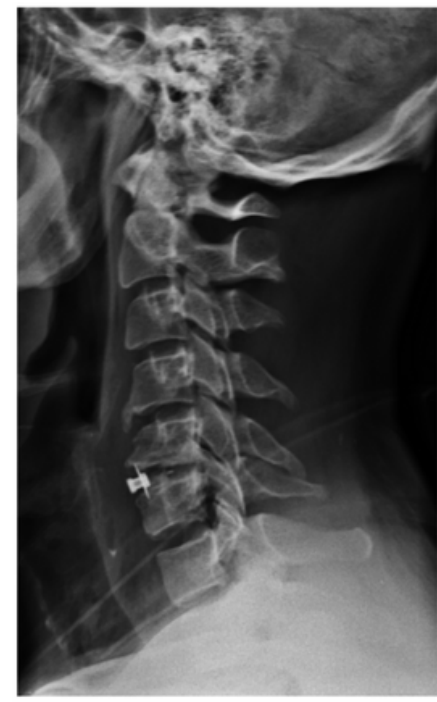

A

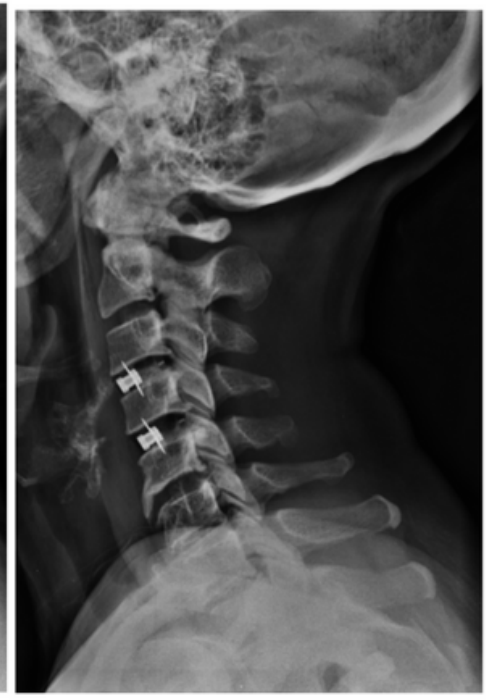

B

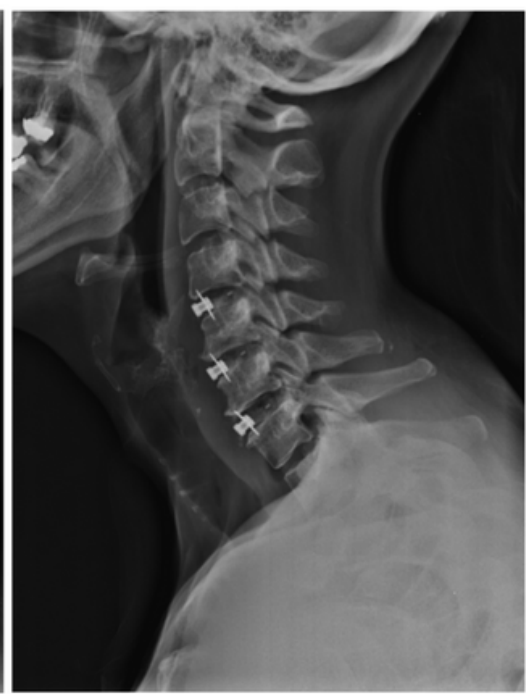

C

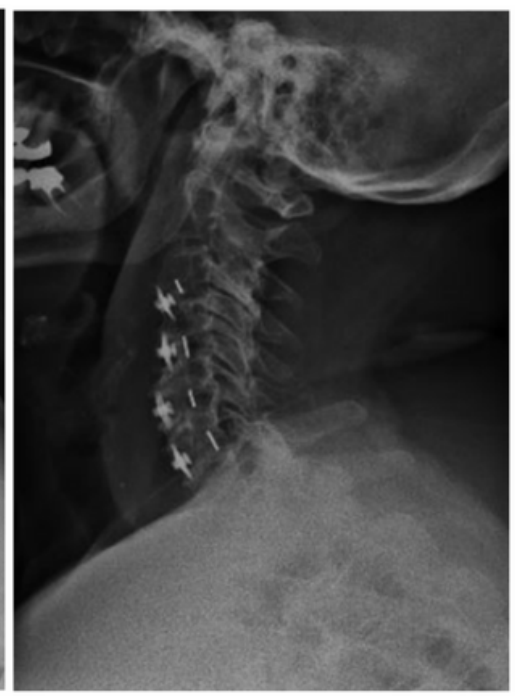

D

\section{Figure 1}

Lateral control radiographs of anterior cervical fusion using Zero-profile implants. One operated level (A), two operated levels (B), three operated levels (C), and four operated levels (D). The incidence of complications increased with the number of operated levels.

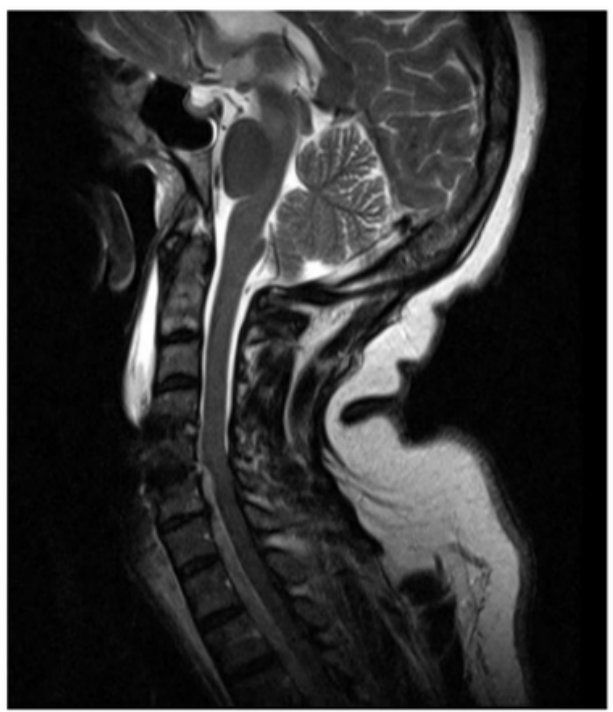

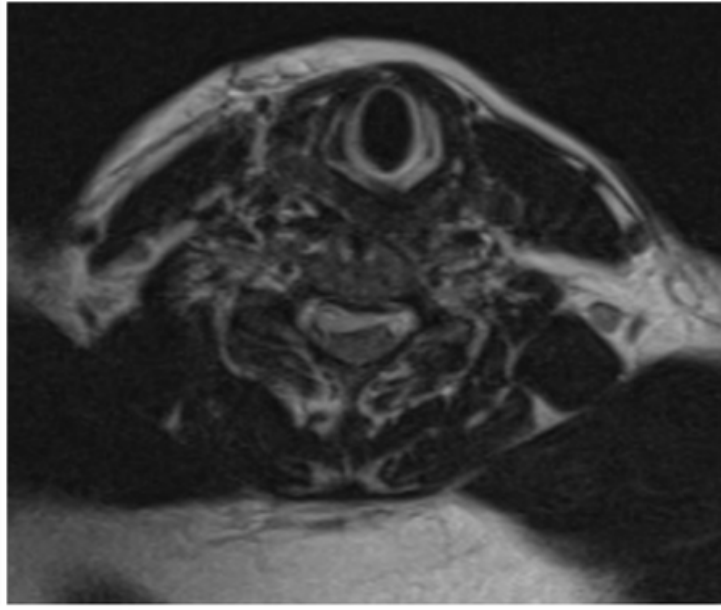

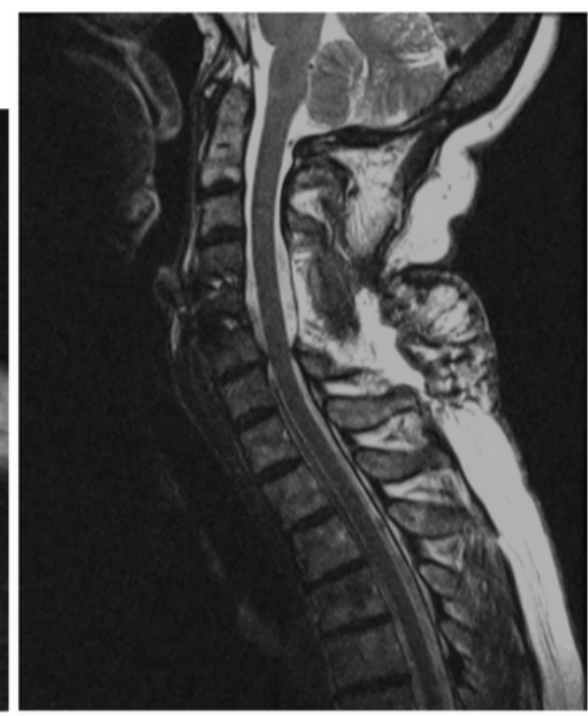

\section{Figure 2}

A patient who developed paraparesis in the immediate postoperative period. Sagittal (A) and Axial (B) T2weighted magnetic resonance imaging showing an epidural hematoma at C6-T8. The patient was taken to the operating room and subjected to laminectomy and posterior drainage of the hematoma (C). 